
ildren shoes, for it is abviousiy that the available size systems currently, such English system, American system and French system are not suitable with donesian foot sizes. Samples of the research were taken from children foot zes of DIY using area purposive sampling, while data analysis method used as Statistical of M (Mean) and SD (Standard of Deviation). The foot size data ere calculated using comparison parameter of breadth to length size, joint rth, instep girth and short heel. Result of the research showed that the icrease of each size number was $6,75 \mathrm{~mm}$; breadth figure and joint, girth size ot a raise in, successively of $2,75 \mathrm{~mm}$ and $6,25 \mathrm{~mm}$ in harmony for each size umber, which were classififield into narrow. medium and wide fitting.

\title{
IN TISAR I
}

Penelitian ini bertujuan untuk menyusun standard ukuran sepatu anaknak Indonesia, karena ternyata sistem ukuran yang ada sekarang ini, yaitu istem ukuran Inggris, Amerika atau Perancis tidak sesuai dengan ukuran kaki hdonesia. Sampel penelitian mengambil ukuran kaki anak-anak di Daerah Istinewa Yogyakarta secara Area purposive sampling, sedang analisa data mengguakan statistik M (Mean) dan SD (Standard Deviasi). Data ukuran kaki diolah engan parameter pembanding ukuran lebar terhadap ukuran panjang, gemur, emuk dan tumit kaki. Hasil Penelitian menunjukkan bahwa kenaikan untuk etiap nomor ukuran adalah $6,75 \mathrm{~mm}$, angka iebar $2,75 \mathrm{~mm}$ dan ukuran gemur ecara serasi naik $6,25 \mathrm{~mm}$ untuk setiap nomor ukuran, yang dibagi dalam fiting sempit (narrow), sedang (medium) dan longgar (wide).

\section{PENDAhuluan}

Menurut Verster (1955), mengatakan bahwa sepatu yang di produksi umumnya dibuat berdasarkan standar ukuran sepatu dari Eropa dan Amerika. Hal ini terbukti bahwa sepatu yang diproduksi sampai saat ini mengacu pada sistem ukuran Inggris, Amerika atau Perancis. Sehingga standard ukuran sepatu tersebut disusun menurut standar ukuran dan kesesuaian pakai (fitting) kaki orang-orang Eropa dan Amerika.

Disisi lain, apabila ditinjau secara anatomis, maka ukuran kaki orang Eropa dan Amerika berbeda dengan ukuran kaki orang Indonesia (Asia). $\mathrm{Hal}$ ini dipengaruhi adanya faktor-faktor : ras (suku bangsa), genetik, makanan/gizi, gerakan/aktifitas serta letak geografis yang berbeda, (Karimoddin 1967, dan Daldjoeni 1982).

Menurut R.G. Miller (1976), bahwa kaki anak-anak pria umur interval 5 - 11 tahun, mempunyai pertumbuhan kaki yang sangat cepat, rata-rata dalam 1 (satu) tahum bertambah 1 ukuran.

Dengan memperhatikan hal-hal tersebut diatas, maka penelitian standard ukuran anak-anak Indonesia ini dilaksanakan dengan tujuan untuk menyusun suatu sistem ukuran sepatu yang berbeda dengan sistem ukuran sepatu yang berbeda dengan sistem ukuran sepatu dari Eropa/Amerika, yang sesuai dengan ukuran dan fitting kaki orang Indonesia.

Penelitian ini dilaksanakan selama 5 (lima) bulan, dari bulan Mei s/d bulan September 1992, dengan mengambil sampel di Daerah Istimewa Yogyakarta.

\section{MATERI DAN METODA PENELITIAN.}

\section{A. Materi}

1. Materi penelitian adalah kaki anak-anak pria murid Taman kanak dan murid Sekolah Dasar yang mempunyai interval umur $5-11$ tahun, yaitu anak-anak yang biasa memakai sepatu dan yang tidak biasa memakai sepatu. Jumlah sampel semuanya ada $\mathbf{3 3 6}$ anak.

2. Lokasi penelitian dilaksanakan di D.I. Yogyakarta, meliputi 4 Kabupaten dan 1 Kotamadya yaitu :
a. Kabupaten Sleman.
b. Kabupaten Bantul.
c. Kabupaten Kulonprogo.

Vol. IX No. 16 Tahun 1993/1994 


\section{d. Kabupaten Gunungkidul.}

e. Kotamadya Yogyakarta.

B. Metoda.

1. Pengambilan sampel dilakukan secara area Purposive sampling (Supranto, 1971 dan Sutrisno Hadi, 1978) DIY, yang terdiri dari 4 kabupaten dan 1 Kotamadya, kemudian dibagi dalam daerah daerah kecamatan. Dari Setiap Kabupaten/Kodya diambil 2 kecamatan sebagai sampel daerah dengan ketentuan sebagai berikut :

a. Diambil 1 (satu) kecamatan yang terletak di daerah kota, untuk mewakili anak-anak yang biasa memakai sepatu :

1). TK dan SD Keputran I Kraton, Yogyakarta.

2). TK dan SD Medari I, Sleman.

3). TK dan SD Bantul I, Bantul.

4). TK dan SD Wates II, Wates Kulonprogo.

5). TK dan SD Wonosari V, Wonosari Gunungkidul.

b. Diambil 1 (satu) kecamatan yang terletak dipelosok desa/pinggir kota, mewakili anak-anak sekolah yang tidak biasa memakai sepatu :

1). TK dan SD Inpres Patang Puluhan Wirobrajan, Yogyakarta.

2). TK dan SD Dalangan, Minggir, Sleman.

3). TK dan SD Inpres Mates, Kasihan, Bantul.

4). TK dan SD Lebeng, Sentolo, Kulonprogo.

5). TK dan SD Ngunut, Playen, Gunungkidul.

2. Pengambilan sampel responden dilakukan secara Purposive Sampling, tetapi dalam kelompok terpisah, yaitu kelompok anak yang biasa memakai sepatu dan kelompok anak yang tidak biasa memakai sepatu. Dari masing-masing kelompok tersebut kemudian ditentukan strata umur 5 - 11 tahun, dan diambil 2 (dua) sampel dengan bulan kelahiran dari Januari s/d Desember, guna mengetahui tingkat perlumbuhan/perkembangan kaki anak tersebut. Jumlah sampel yang didapat semua ada 336 sampel ( 2 jenis kaki $x 7$ kelompok umur $\times 12$ bulan kelahiran $\mathrm{x}$ masing-masing 2 sampel).

3. Pengukuran Kaki.

Pengukuran kaki dikerjakan pada kaki kanan dan kaki kiri menurut Bata (1977), sebagai berikut :

a. Mengukur panjang telapak kaki (length).

b. Mengukur lebar telapak kaki (breadth). c. Mengukur gemur kaki (Joint girth).

d. Mengukur gemuk kaki (instep girth).

e. Mengukur tumit kaki (short heel).

4. Analisa data.

Data sampel responden dianalisa secara statistik, dengan menghitung rata-rata (Mean) dan Standard Deviasi, menurut Sutrisno Hadi, 1978

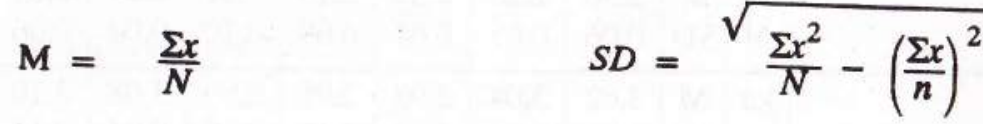

\section{HASIL PENELITIAN DAN PEMBAHASAN}

\section{A. Hasil Penelitian.}

Pengukuran kaki dilaksanakan terhadap murid-murid taman kanakkanak dan murid SD DI Yogyakarta, meliputi kaki anak-anak yang biasa memakai sepatu dan anak-anak yang tidak biasa memakai sepatu.

\section{B. Analisa data.}

1. Angka lebar kaki sebagai parameter pembanding.

Dalam penelitian ini, angka lebar (breadth) ditetapkan sebagai parameter pembanding terhadap ukuran-ukuran yang lain (panjang telapak kaki, gemur kaki, gemuk kaki dan tumit kaki). Hal ini sesuai dengan pendapat Manning (1965) dan Ramanathan, et al (1974).

Hasil perhitungan seperti terlihat pada tebel 1 dan tabel 2 dibawah ini.

Tabel 1. : Mean dan Standard Deviasi ukuran-ukuran kaki dibandingkan dengan angka lebar sebagai parameter pembanding.

\begin{tabular}{|c|c|c|c|c|c|c|c|c|c|}
\hline \multicolumn{3}{|c|}{ Umur (tahun) } & 5 & 6 & 7 & 8 & 9 & 10 & 11 \\
\hline \multicolumn{10}{|c|}{ A. Anak-anak yang memakai sepatu } \\
\hline \multirow{4}{*}{$\begin{array}{l}\text { Pj. T. } \\
\text { K/Lebar }\end{array}$} & \multirow[t]{2}{*}{ ka } & \multirow{2}{*}{$\begin{array}{c}\mathrm{M} \\
\mathrm{SD}\end{array}$} & 2,43 & 2,49 & 2,41 & 2,42 & 2,47 & 2,53 & 2,51 \\
\hline & & & 0,08 & 0,05 & 0,08 & 0,10 & 0,04 & 0,08 & 0,08 \\
\hline & \multirow[b]{2}{*}{ ki } & $\mathbf{M}$ & 2,25 & 2,48 & 2,48 & 2,42 & 2,50 & 2,53 & 2,51 \\
\hline & & SD & 0,10 & 0,07 & 0,09 & 0,10 & 0,05 & 0,09 & 0,11 \\
\hline
\end{tabular}




\begin{tabular}{|c|c|c|c|c|c|c|c|c|c|}
\hline \multirow{4}{*}{ Gemur/Lebar } & ka & M & 2,27 & 0,28 & 0,21 & 0,21 & 0,21 & 0,25 & 0,26 \\
\hline & & $\mathrm{SD}$ & 0,10 & 0,06 & 0,08 & 0,10 & 0.11 & 0,04 & 0,05 \\
\hline & & $\mathrm{M}$ & 2,28 & 2,27 & 2,24 & 2,20 & 2,20 & 2,23 & 2,22 \\
\hline & ki & SD & 0,08 & 0,06 & 0,06 & 0,06 & 0,10 & 0,05 & 0,04 \\
\hline \multirow{4}{*}{ Gemuk/Lebar } & ka & M & 2,29 & 2,29 & 2,19 & 2,20 & 2,20 & 2,25 & 2,25 \\
\hline & & $\mathrm{SD}$ & 0,07 & 0,04 & 0,06 & 0,07 & 0,08 & 0,03 & 0,05 \\
\hline & & $\mathrm{M}$ & 2,30 & 2,28 & 2.23 & 2,19 & 2,21 & 2,24 & 2,24 \\
\hline & ki & $\mathrm{SD}$ & 0,06 & 0,05 & 0,04 & 0,09 & 0,10 & 0,04 & 0,06 \\
\hline \multirow{4}{*}{ Tumit/Lebar } & ka & M & 3,02 & 3,04 & 2,93 & 2,95 & 2,99 & 3,08 & 3,10 \\
\hline & & SD & 0,08 & 0,04 & 0,09 & 0,13 & 0,08 & 0,06 & 0,11 \\
\hline & & M & 3,04 & 3,05 & 2,97 & 2,97 & 3,03 & 3,08 & 3,07 \\
\hline & ki & SD & 0,08 & 0,09 & 0,05 & 0,13 & 0,14 & 0,06 & 0,09 \\
\hline
\end{tabular}

B. Anak-anak yang tidak memakai sepatu

\begin{tabular}{|c|c|c|c|c|c|c|c|c|c|}
\hline \multirow{4}{*}{$\begin{array}{c}\text { Pj. T. } \\
\text { K/Lebar }\end{array}$} & $\mathrm{ka}$ & M & 2,27 & 2,28 & 2,40 & 2,40 & 2,52 & 2,47 & 2,44 \\
\hline & & $\mathrm{SD}$ & 0,07 & 0,06 & 0,07 & 0,06 & 0,07 & 0,08 & 0,07 \\
\hline & & M & 2.41 & 2,38 & 2,40 & 2,44 & 2,46 & 2,48 & 2,48 \\
\hline & ki & $\mathrm{SD}$ & 0,07 & 0,05 & 0,09 & 0,08 & 0,08 & 0,08 & 0,08 \\
\hline \multirow{4}{*}{ Gemur/Lebar } & ka & M & 2,23 & 2,22 & 0,18 & 0,21 & 0,21 & 0,26 & 0,24 \\
\hline & & SD & 0,05 & 0.09 & 0,05 & 0,05 & 0,07 & 0,07 & 0,05 \\
\hline & & $\mathbf{M}$ & 2,25 & 2,22 & 2,24 & 2,24 & 2,22 & 2,24 & 2,25 \\
\hline & ki & $\mathrm{SD}$ & 0,07 & 0,08 & 0,08 & 0,08 & 0,08 & 0,06 & 0,07 \\
\hline \multirow{4}{*}{ Gemuk/Lebar } & ka & M & 2,25 & 2.24 & 2,19 & 2,22 & 2,21 & 2,26 & 2,24 \\
\hline & & $\mathrm{SD}$ & 0,05 & 0,08 & 0,06 & 0,06 & 0,07 & 0,07 & 0,05 \\
\hline & & $\mathbf{M}$ & 2,25 & 2,24 & 2,19 & 2,25 & 2,24 & 2,26 & 2,25 \\
\hline & ki & $\mathrm{SD}$ & 0,07 & 0,07 & 0,05 & 0,05 & 0,09 & 0,06 & 0,08 \\
\hline \multirow{4}{*}{ Tumit/Lebar } & ka & M & 2,93 & 2,94 & 2,93 & 2,97 & 2,98 & 3,10 & 3,00 \\
\hline & & SD & 0,08 & 0,12 & 0,08 & 0,09 & 0,09 & 0,12 & 0,06 \\
\hline & & M & 3,00 & 2,94 & 2,94 & 3,03 & 3,03 & 3,12 & 3,14 \\
\hline & $\mathbf{K} \mathbf{1}$ & SD & 0,07 & 0,09 & 0,08 & 0,10 & 0,11 & 0,12 & 0,13 \\
\hline
\end{tabular}

Keterangan: $\mathrm{Pj} . \mathrm{tk}=$ Panjang telapak kaki.

$$
\begin{aligned}
& \mathrm{Ka}=\text { Kanan. } \\
& \mathrm{Ki}=\text { Kiri. } \\
& \mathrm{M}=\text { Mean. } \\
& \mathrm{SD}=\text { Standar Deviasi. }
\end{aligned}
$$

\begin{tabular}{|c|c|c|c|c|}
\hline No. & Perbandingan & A & B & Rata-rata \\
\hline $\begin{array}{l}1 . \\
2 . \\
3 . \\
4 .\end{array}$ & $\begin{array}{l}\text { Pj. tk/Lebar } \\
\text { Gemur/Lebar } \\
\text { Gemuk/Lebar } \\
\text { Tumit/Lebar }\end{array}$ & $\begin{array}{l}2,475 \\
2,235 \\
2,240 \\
3,020\end{array}$ & $\begin{array}{l}2,425 \\
2,225 \\
2,235 \\
3,015\end{array}$ & $\begin{array}{l}2,45 \\
2,23 \\
2,24 \\
3,02\end{array}$ \\
\hline
\end{tabular}

Tabel 2 : Hasil Perbandingan Ukuran-Ukuran kaki dengan angka lebar, sebagai parameter pembanding.

\section{Keterangan: $\mathrm{Pj}$. tk = Panjang telapak kaki.}

$$
\begin{array}{ll}
\mathrm{A} & =\text { Anak-anak yang memakai sepatu. } \\
\mathrm{B} & =\text { Anak-anak yang tidak memakai sepatu. }
\end{array}
$$

2. Menghitung pertumbuhan dan perkembangan ukuran kaki.

untuk menghitung pertumbuhan dan perkembangan ukuran kaki di-

\begin{tabular}{|c|c|c|c|c|c|c|c|c|}
\hline \multirow{2}{*}{$\begin{array}{c}\text { Umur } \\
\text { (th) }\end{array}$} & \multicolumn{4}{|c|}{ Periode 4 bulan ( $\mathrm{mm}$ ) } & \multicolumn{4}{|c|}{ Periode 8 bulan $(\mathrm{mm})$} \\
\hline & Pj. tk & $d p_{1}$ & Lebar & $\mathrm{dl}_{1}$ & Pj. tk & $\mathrm{dp}_{2}$ & Lebar & $\mathrm{dl}_{2}$ \\
\hline $\begin{array}{r}5 \\
6 \\
7 \\
8 \\
9 \\
10 \\
11\end{array}$ & $\begin{array}{l}170,5 \\
177 \\
186,5 \\
190,5 \\
199 \\
203,5 \\
208\end{array}$ & $\begin{array}{l}6,5 \\
9,5 \\
4 \\
8,5 \\
4,5 \\
4,5\end{array}$ & $\begin{array}{l}70 \\
72,5 \\
76 \\
79 \\
81 \\
82 \\
85,5\end{array}$ & $\begin{array}{c}2,5 \\
3,5 \\
3 \\
2 \\
1 \\
35\end{array}$ & $\begin{array}{l}171 \\
179 \\
188 \\
195,5 \\
205 \\
210 \\
213\end{array}$ & $\begin{array}{l}8 \\
9 \\
7,5 \\
9,5 \\
5 \\
3\end{array}$ & $\begin{array}{l}70,5 \\
73 \\
77,5 \\
80 \\
83 \\
85 \\
87\end{array}$ & $\begin{array}{l}2,5 \\
4,5 \\
2,5 \\
3 \\
2 \\
2\end{array}$ \\
\hline \multicolumn{2}{|c|}{ Jumlah } & 37,5 & & 15,5 & & 42 & & 16,5 \\
\hline
\end{tabular}
tentukan dengan cara menghitung pertambahan ukuran selama interval waktu 4 (empat) bulan dan 8 (delapan) bulan. Hasil perhitungan seperti tabel. 3 dibawah ini.

Tabel 3 : Pertumbuhan dan perkembangan ukuran kaki selama interval waktu 4 bulan dan 8 bulan.

Keterangan: $d p_{1}=$ Pertumbuhan panjang, interval 4 bulan.

$$
\begin{aligned}
& \mathrm{dl}_{1}=\text { Perkembangan lebar, interval } 4 \text { bulan. } \\
& \mathrm{dp}_{2}=\text { Pertumbuhan panjang, interval } 8 \text { bulan. } \\
& \mathrm{dl}_{2}=\text { Perkembangan lebar, interval } 8 \text { bulan. }
\end{aligned}
$$

Vol. IX No. 16 Tahun 1993/1994
69 


\section{Berdasarkan tabel diatas maka didapatkan :}

a. Rata-rata pertumbuhan panjang telapak kaki selama interval 4 bulan $(\mathrm{dp} 1)=37,5: 6=6,25$ dibulatkan $6,50 \mathrm{~mm}$.

b. Rata-rata perkembangan lebar telapak kaki selama interval waktu 4 bulan $\left(\mathrm{dl}_{1}\right)=15,5: 6=2,58$ dibulatkan $2,50 \mathrm{~mm}$.

c. Rata-rata pertumbuhan panjang telapak kaki selama interval waktu 8 bulan $\left(\mathrm{dp}_{2}\right)=42: 6=7,00 \mathrm{~mm}$

d. Rata-rata perkembangan lebar telapak kaki selama interval waktu 8 bulan $\left(\mathrm{dl}_{2}\right)=16,5: 6=2,75$ dibulatkan $3,00 \mathrm{~mm}$.

Untuk menentukan pertumbuhan dan perkembangan ukuran kaki, maka dihitung pertumbuhan dan perkembangan ukuran kaki selama 6 bulan, sehingga hasilnya sebagai berikut : a. Pertumbuhan ukuran panjang telapak kaki $=\left(\frac{6,50+7,00}{2}\right) \mathrm{mm}$
$=6,75 \mathrm{~mm}$. b. Perkembangan ukuran lebar telapak kaki $=\left(\frac{2,50+3,00}{2}\right) \mathrm{mm}=$
$2,75 \mathrm{~mm}$.

Sesuai dengan perhitungan pada tabel 2, bahwa perbandingan panjang telapak kaki dengan angka lebar sebagai parameter pembanding adalah angka 2,45 maka dari angka perkembangan ukuran lebar telapak kaki 2,75 akan diperoleh pertumbuhan panjang telapak kaki sebesar $(2,45 \times 2,75) \mathrm{mm}=6,74 \mathrm{~mm}$. Angka ini serasi dengan pertumbuhan ukuran panjang telapak kaki selama 6 bulan yaitu 6,75 $\mathrm{mm}$.

3. Menetapkan standar ukuran dan fitting.

Berdasarkan perhitungan pada tabel 2 maka dapat disusun suatu patokan perhitungan untuk menentukan standar ukuran sepatu anakanak dan fitting, seperti tersebut pada tabel 4 dibawah ini.
Tabel 4 : Penyusunan patokan untuk menentukan standar ukuran kaki dan fitting (dalam $\mathrm{mm}$ ).

\begin{tabular}{|c|l|l|l|l|}
\hline \multicolumn{5}{|c|}{ Panjang telapak kaki =2,45 x lebar $(\mathrm{mm})}$. \\
\hline \multicolumn{1}{|c|}{ Lebar } & \multicolumn{1}{|c|}{ Gemur } & \multicolumn{1}{c|}{ Gemuk } & \multicolumn{1}{c|}{ Tumit } & fitting \\
\hline $\mathrm{L}$ & $2,23 \mathrm{~L}$ & $2,24 \mathrm{~L}$ & $3,02 \mathrm{~L}$ & Sedang \\
$(\mathrm{L}+2,75)$ & $2,23 \mathrm{x}$ & $2,24 \mathrm{x}$ & $3,02 \mathrm{x}$ & \\
& $(\mathrm{L}+2,75)$ & $(\mathrm{L}+2,75)$ & $(\mathrm{L}+2,75)$ & Agak longgar \\
$(\mathrm{L}+5,5)$ & $2,23 \mathrm{x}$ & $2,24 \mathrm{x}$ & $3,02 \mathrm{x}$ & \\
& $(\mathrm{L}+5,5)$ & $(\mathrm{L}+5,5)$ & $(\mathrm{L}+5,5)$ & Longgar \\
& $2,23 \mathrm{x}$ & $2,24 \mathrm{x}$ & $3,02 \mathrm{x}$ & \\
$(\mathrm{L}-2,75)$ & $(\mathrm{L}-2,75)$ & $(\mathrm{L}-2,75)$ & $(\mathrm{L}-2,75)$ & Agak sempit \\
& $2,23 \mathrm{x}$ & $2,24 \mathrm{x}$ & $3,02 \mathrm{x}$ & \\
$(\mathrm{L}-5,5)$ & $(\mathrm{L}-5,5)$ & $(\mathrm{L}-5,5)$ & $(\mathrm{L}-5,5)$ & Sempit \\
\hline
\end{tabular}

Keterangan : L = Lebar standar ukuran sepatu.

Berdasarkan tabel 4 diatas, maka secara rinci dapat disusun sistem ukuran sepatu dan fitting untuk sepatu anak-anak pria seperti terlihat pada tabel 5 dibawah ini. 


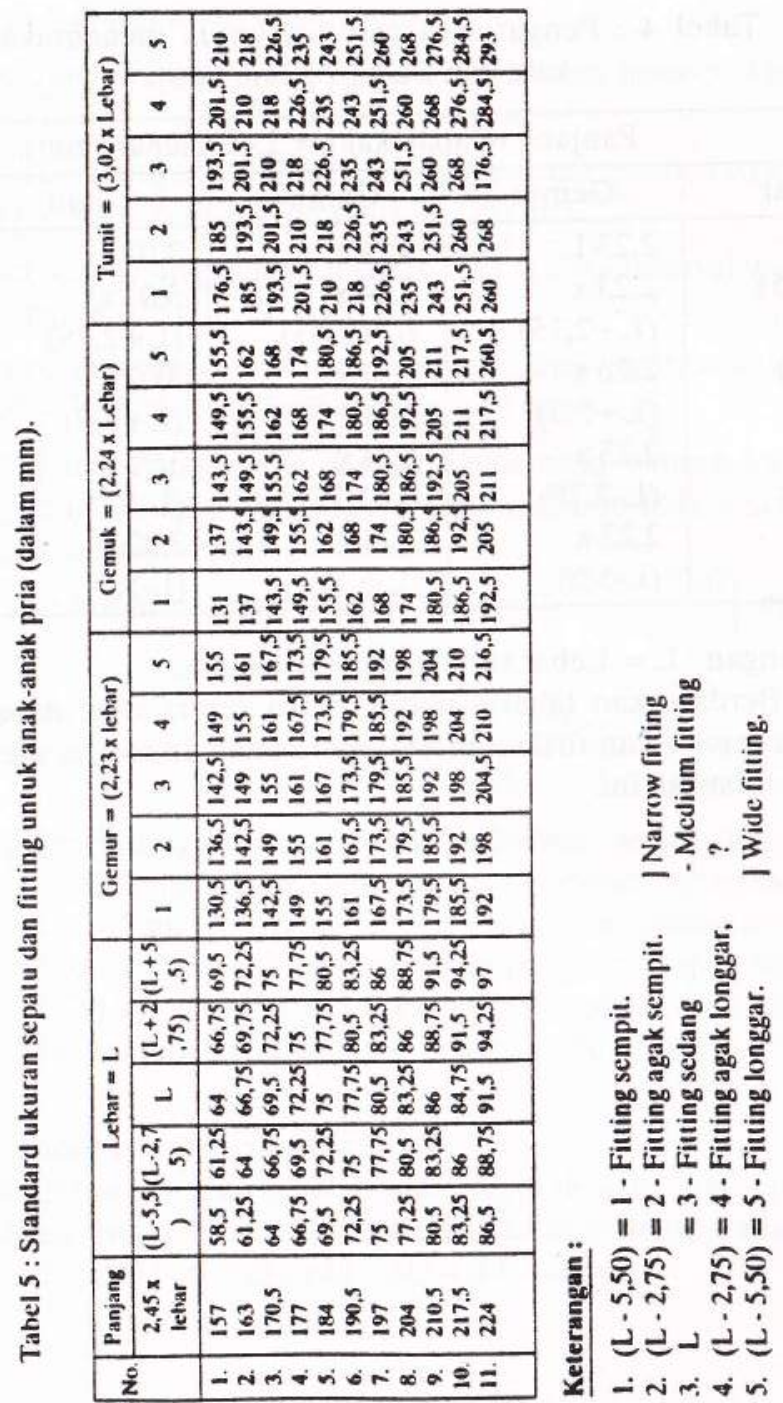

\section{Pembahasan.}

Menurut sistem Inggris, penambahan ukuran panjang sepatu untuk setiap ukuran adalah sebesar 0,33 inci $(8,45 \mathrm{~mm})$ dan untuk setengah ukuran adalah sebesar 0,166 inci $(4,25 \mathrm{~mm})$. Sedangkan menurut sistem Perancis, untuk setiap kenaikan nomor sepatu, ukuran panjang bertambah $6,66 \mathrm{~mm}$. Berbeda dengan hasil penelitian ini bahwa untuk setiap kenaikan nomor sepatu, maka ukuran panjang bertambah $6,75 \mathrm{~mm}$, hal ini sesuai dengan ukuran kaki orang Indonesia.

Menurut Verster (1955), penambahan untuk setiap kenaikan ukuran gemur kaki (fitting) adalah sebesar $5 \mathrm{~mm}$, dengan notasi fitting yang tak terbatas (A,B,C,D, dst), tanpa pengelompokan, sehingga akan menyulitkan kelompok ukuran mana untuk fitting tersebut. Sedangkan hasil penelitian menunjukkan bahwa secara serasi penambahan untuk setiap kenaikan ukuran gemur adalah sebesar $6,25 \mathrm{~mm}$ dan dikelompokan dalam fitting sempit (narrow), fitting sedang (medium) serta fitting longgar (wide).

\section{Kesimpulan.}

1. Untuk menetapkan standar ukuran sepatu, maka sebagai parameter pembanding adalah angka lebar, dengan ketentuan sebagai berikut :

a. Panjang telapak kaki : lebar $=2,45$

b. Gemur : lebar $=2,23$

c. Gemur : lebar $=2,24$

d. Tumit : lebar $=3,02$

2. Kenaikan untuk setiap nomor ukuran sepatu adalah :

Panjang $=6,75 \mathrm{~mm}$.

Gemur $=6,25 \mathrm{~mm}$.

Ukuran tersebut dikelompokan dalam fitting sempit (narrow), sedang (medium) dan longgar (wide).

3. Sistem ukuran yang ada (Inggris, Amerika, Perancis), baik dalam pemberian notasi, fitting maupun penambahan untuk setiap ukurannya, ternyata tidak sesuai dengan standard ukurannya, ternyata tidak sesuai dengan standard ukuran kaki orang Indonesia, khususnya untuk kaki anak-anak pria.

Vol. IX No. 16 Tahun 1993/1994 


\section{KEPUSTAKAAN.}

1. Anonimous, 1977. Footwear Design and Manufacture. Bata shoe Company Private Limited, Main Factory Bata nagar India.

2. Daldjoeni N, 1982. Pengantar Geografi. Penerbit Alumni, Bandung.

3. Miller, RG (editor), 1978, + th. edition Manual of Shoemaking, Clarks Limited.

4. Karimoddin A.T, 1967, Ilmu Kesehatan Balai Pustaka, Jakarta.

5. Ramanatan et al, 1974, Standard Footwear Sizes for Children. UNIDO, Madras, India.

6. Suprapto, 1971, Metode Riset. Fakultas Ekonomi Universitas Indone- sia, Jakarta.

7. Sutrisno Hadi, 1978. Metodologi Research, Jilid I, Fakultas Psikologi, Universitas Gadjah Mada Yogyakarta.

8. Verster, CL (1955). Penuntun ke Perusahaan Sepatu, Balai Pustaka, Jakarta. 